\title{
O CR-P nas eleições de 1998 para o governo gaúcho - a vitória da contra-hegemonia Maria Alice Boelhouwer Lussani
}

\begin{abstract}
RESUMO
O artigo "O CR-P nas eleições de 1998 para o Governo Gaúcho. A vitória da contra-hegemonia" tem por objetivo apresentar os resultados iniciais da pesquisa sobre as eleiçōes de 1998 no Rio Grande do Sul para o governo do estado. A análise vai ser desenvolvida a partir do conceito de Cenário de Representaçāo Politica (CR-P) e da hipótese de agenda setting. A hipótese central do trabalho é a de que alguns meios de comunicaçāo construíram um cenário para garantir a vitória do candidato Antônio Britto (PMDB) já no primeiro turno, mas a construçāo de um outro CR-P, alternativo, levou o candidato Olivio Dutra (PT) ao segundo turno e à vitória nas eleições.
\end{abstract}

A B STRACT

This paper "The CR.P in the elections of 1998 to the RS Government: The victory of counter-hegemony", aims to present the initial results of the research about the elections of 1998. The analysis will be developed from the concept of Scenery of Politics Representation (CR-P) and from the hypothesis of agenda setting. The central hypothesis of this paper is that some means of communication built a scenery to assure the victory of the candidate Antonio Britto (PMDB) in the first turn, but the construction of another CR-P, alternative, lead the candidate Olivio Dutra (PT) to the second turn and to victory of the elections.

Maria Alice Boelhouwer Lussani, mestranda do Curso de Mestrado em Comunicação da Pontificia Universidade Católica do Rio Crande do Sul (PUCRS), sob orientaçăo do Prof. Or. Antonio Hohlfeldt, é jornalista formada pela Universidade Federal do Rio Grande do Sul (UFRCS), especialista em Teoria do Jornalismo e Comunicação de Massa pela PUCRS, e atualmente exerce a função de Editora.Chefe do Jornal da Cidadania na TVE/RS. 


\section{O CR-P nas eleições de 1998 para o governo gaúcho A vitória da contra-hegemonia}

As eleições são um momento de afirmação democrática de uma nação. Se as decisões políticas, de forma geral, são tomadas no dia-a-dia, em uma eleição se reafirma a disposição de dar continuidade ou não a um projeto de governo ou a uma proposta de nação. As eleições de 1998 foram um destes momentos de reafirmação da democracia brasileira, apesar de todas as denúncias de corrupção, do uso da máquina pública, do favorecimento de candidatos e de manipulação de pesquisas e informações pela mídia. $O$ presente artigo busca captar este momento histórico nas eleições para o governo do estado do Rio Grande do Sul a partir dos conceitos de CR-P e agenda setting.

\section{Os conceitos de CR-P e de Agenda Setting}

O conceito de Cenário de Representação da Política, CR-P, proposto por Venicio Lima,! coloca três pressupostos básicos para sua identificação. Em primeiro lugar, a existência de uma sociedade media-centered, que tenha como característica sistemas nacionais consolidados de comunicações. $\mathrm{Na}$ política, a centralidade da mídia se dá pelo papel capital que tem de cimentar e unificar o bloco social hegemônico, como principal aparelho privado de hegemonia.

Em segundo lugar, o exercício de uma hegemonia, que implica em uma sociedade ocidentalizada com alto grau de socialização da política, constituindo-se de uma sociedade política (aparelho coercitivo do Estado) e de uma sociedade civil, e com a permanente possibilidade de que classes ou frações de classe protagonizem disputas internas e/ou externas pela direção e pelo consenso. Para Gramsci, hegemonia é algo que não apenas opera sobre a estrutura econômica e sobre a organização politica da sociedade, mas também sobre o modo de pensar, sobre as orientações ideológicas $e$ inclusive sobre o modo de conhecer. ${ }^{2}$ Mais adiante, diz que a hegemonia é: determinar os traços especificos de uma condição histórica, de um processo, tornar-se protagonista de reivindicações que são de outros estratos sociais, da solução das mesmas, de modo a unir em torno de si esses estratos, realizando com eles uma aliança na luta contra o capitalismo $e$, desse modo, isolando o próprio capitalismo. ${ }^{3}$

Como diz Mauro Porto, a hegemonia não é uma forma passiva de dominação, pois é continuamente desafiada e defendida, em uma luta constante na qual a correlação de forças na sociedade civil (o próprio locus da hegemonia) tem um papel decisivo. ${ }^{4}$

Em terceiro lugar, a existência da tv como meio dominante, mas não como único e exclusivo, já que a análise vai ter que levar em conta os outros meios, como emissoras de rádio, jornais, revistas e cinema. 
A aplicação do conceito de CR-P à compreensão e análise dos processos eleitorais requer algumas condições. Uma delas é a de que os candidatos em disputa eleitoral representem interesses em conflito que possam ser traduzidos em termos de competição intra-hegemônica entre classes do bloco histórico no poder ou em termos de competição entre, de um lado, classes e/ou frações de classe do bloco histórico que defendem a manutenção da hegemonia dominante e, de outro, classes e/ou frações de classe que buscam uma nova articulação hegemônica. A identificação de um CR-P contra-hegemônico é que vai expressar na prática o reconhecimento da viabilidade politica da alternância do hegemônico, do caráter dinâmico da hegemonia e, portanto, do CR-P, que deve ser continuamente renovado, recriado, defendido e modificado porque é continuamente resistido, limitado, alterado e desafiado. ${ }^{5}$

Se o conceito de CR-P nos mostra o caminho do que deve ser analisado, a partir de que perspectiva e porquê, a hipótese de agenda setting diz como deve ser feito, ou seja, no presente estudo vai ser útil principalmente na análise dos jornais diários. Kucinski define a função da agenda da seguinte maneira: O processo midiático de produção do consenso tem inicio na definição da agenda nacional de discussões. É mediante a inclusão ou exclusão dos itens na agenda, ou dos enfoques adotados, que se inicia a construção do consenso. (...) Opera principalmente reforçando crenças previamente existentes. ${ }^{6}$

A agenda funciona de maneira circular. A notícia nasce, é pautada pelos jornais, é distribuída pelas agências de notícias, transforma-se em pauta para os telejornais, para os programas de rádio, acaba sendo o assunto das revistas semanais, dos debates e comentários e é consumida por leitores, telespectadores e ouvintes. É esta seleção de assuntos, efetuada pelo público em função da ação dos jornais, televisão e outros meios de comunicação, e pelos próprios veículos, conforme seus interesses, que se define como agenda setting. Entre as características dos meios que são importantes para a construção desta hipótese, estão o de acumulação (capacidade de criar e manter a relevância de um tema), consonância (traços comuns entre os meios definem mensagens semelhantes) e onipresença (o saber público difundido pelos meios é de domínio público).

Esta hipótese tem como pressuposto que a compreensão que as pessoas têm de grande parte da realidade social lhes é fornecida, por empréstimo, pelos meios de comunicação, a médio e longo prazos. Como bem destaca Mauro Wolf, em conseqüencia da ação dos jornais, da televisão e dos outros meios de informação, o público sabe ou ignora, presta atenção ou descura, realça ou negligencia elementos especificos dos cenários públicos. ${ }^{\top}$ 


\section{As eleições em 1998}

Mais de 106 milhões de eleitores, dos quais $31,42 \%$ analfabetos, ou seja, 33.331.283 eleitores, ${ }^{8}$ foram às urnas eleger o presidente da República, 27 governadores, 27 senadores, 513 deputados federais e 1045 deputados estaduais. E com uma novidade: a urna eletrônica, utilizada por $57,62 \%$ dos eleitores, ou seja, 61.095 .594 de brasileiros. A eleição informatizada já havia sido experimentada em 1996, mas somente para os eleitores das 57 maiores cidades do país. Em 1998, a urna eletrônica chegaria a 537 municípios, todos com mais de 40 mil habitantes, além de todas as cidades dos estados de Amapá, Roraima, Alagoas, Rio de Janeiro e Distrito Federal. ${ }^{9}$ No Rio Grande do Sul, 30 dos 467 municípios utilizaram a urna eletrônica, representando 3.625.124 (52,95\%) dos 6.845.988 de eleitores gaúchos. Além desta novidade, a última eleição do milênio teve outras particularidades. Pela primeira vez, presidente, vice, governadores e prefeitos (que só disputariam a eleição em 2000) poderiam concorrer à reeleição, sem precisar se licenciar dos cargos.

Um editorial da revista Comunicação \& Política, comentando a nova regra, destaca:

A emenda, capenga, dispensou os titulares dos postos executivos da exigência da desincompatibilização. [...] Em compensação, o continuo que serve café estava (e está) obrigado a desincompatibilizar-se, para, nos termos da lei das inelegibilidades, não usar a influência do cargo em proveito eleitoral. [...] E assim se vai cumprindo, eleição após eleição, a antiga máxima peninsular "Lá vão as leis para onde querem os reis". No caso brasileiro, para manter os Principes no poder. ${ }^{10}$

A Conferência Nacional dos Bispos do Brasil (CNBB) também criticou em documento oficial, a adoção desta prática. Embora seja uma opção democrática, sua adoção no Brasil ficou marcada por insuficiências na participação da sociedade e por suspeições pouco favoráveis. A prática das campanhas está mostrando que, em nossa realidade cultural e politica, ela cria grandes riscos de abuso da máquina governamental."

As regras para o pleito também mudaram. O Tribunal Superior Eleitoral permitiu o uso de imagens no Horário de Propaganda Eleitoral Obrigatória (HPEO), ${ }^{12}$ depois de sua proibição nas eleições de 1994.

É neste contexto que vão se dar as eleições no Rio Grande do Sul.

De um lado, Antônio Britto, Governador e candidato à reeleição pelo PMDB, com o apoio de onze partidos ${ }^{13} \mathrm{e}$ do presidente FHC. De outro, Olívio Dutra, do PT, aliado a três partidos de esquerda, ${ }^{14}$ e com o apoio de Luís Inácio Lula da Silva. Dois candidatos, duas propostas totalmente diferentes para o estado.

$\mathrm{O}$ objetivo deste artigo é tentar responder à seguinte questão: por que Olívio Dutra ganhou as eleições para o governo do Estado, se Antônio Britto 
tinha tudo a seu favor, se todo um cenário foi construído para fazê-lo vencer já no primeiro turno? Além de ser candidato à reeleição, com a máquina do governo a seu favor, Britto era o candidato de um quase partido, a RBS, Rede Brasil Sul de Comunicação, afiliada da Rede Globo e o principal veículo de comunicação do Rio Grande do Sul. Em entrevista à revista Carta Capital, Nelson Sirotsky, diretor-presidente da RBS, afirmou que falando com clareza, é isso; somos os donos da opinião pública no sul do pais. ${ }^{15}$ Mendes Ribeiro, colunista do Correio do Povo, comenta o fato, já no início de 1998: Todo mundo sabe que a reeleição foi comprada a peso de muito dinheiro. Ninguém tem dúvida a respeito da Rede Globo e de suas afiliadas tomarem abertamente partido. Não conheço uma só pessoa iludida a respeito do resultado da eleição. Os preferidos de todos os poderosos serão nomeados e não eleitos. Apenas no âmbito regional teremos os espaços do PSDB, $P M D B, P P S, P P, P F L, P T B$, tecendo loas ao executivo. Desancando o PT que, sem tempo, será obrigado a engolir o sapo. Preparem-se, então. Daqui por diante a verdade está proibida. E viva a mentira, a começar pelo excelente governo de $\mathrm{FH}^{16}$

Britto tinha também o apoio de jornalistas e comentaristas políticos da RBS. As pesquisas de opinião pública realizadas por diferentes Institutos de Pesquisa indicavam que o governador licenciado ${ }^{17}$ seria reeleito já no primeiro turno. O então governador tinha ainda o aval de Fernando Henrique Cardoso, presidente da República e candidato à reeleição. A tentativa de ter um candidato próprio do PSDB, o vice-governador Vicente Bogo, concorrendo ao governo do Estado, foi barrada pelo próprio presidente, até com ameaça de intervenção no diretório estadual, se o partido não fizesse aliança com Britto. A aliança entre $\mathrm{FHC}$ e Britto foi tão evidente que o presidente se lançou oficialmente candidato à reeleição num megacomicio no Gigantinho, em Porto Alegre, e declarou, na ocasião: Se o Rio Grande perceber essa parceria, espero que recompense com mais firmeza Britto e que, nessas ondas, eu também cresça ${ }^{18}$ além de manter um comitê de campanha no Estado. Como se isto já não fosse pouco, Britto tinha o apoio da maioria dos empresários e dos grandes partidos do Estado e o maior tempo de televisão no HPEO: 11 minutos e 16 segundos, contra 2 minutos e 52 segundos da Frente Popular de Olívio Dutra. ${ }^{19}$ Tinha ainda a vantagem de ter ganhado as eleições em 1994 contra o mesmo candidato, Olivio Dutra, por uma diferença de pouco mais de quatro por cento dos votos. ${ }^{20}$ Mas Britto não ganhou as eleições. No primeiro turno, venceu com $46,40 \%$ dos votos válidos (2.319.302 votos) contra $45,92 \%$ de Olivio Dutra (2.295.503 votos), uma diferença de apenas $0,48 \%$ dos votos válidos (23.799 votos). E, no segundo turno, perdeu por uma diferença de menos de 100 mil votos. Olivio Dutra obteve $50,78 \%$ do total de votos (2.844.757) contra 49,22\% de Britto (2.757.401). 
Olivio Dutra, da Frente Popular, no segundo turno, recebeu o apoio do PDT, PV e PPS. ${ }^{21} O$ partido vinha crescendo desde as primeiras eleições, em

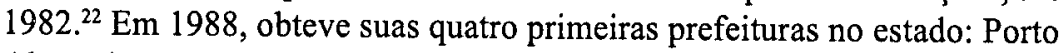
Alegre (com Olívio Dutra, que venceu a disputa contra Antônio Britto), Ronda Alta, Severiano de Almeida e Rio Grande, elegendo 125 vereadores. Em 1990, foram eleitos quatro deputados federais e cinco estaduais. Em 1992, segunda vitória do PT em Porto Alegre, além de sete prefeituras no estado, 8 viceprefeitos e 171 vereadores. Em 1994, mesmo tendo perdido a eleição para o governo do Estado, o partido elegeu 7 deputados federais e 8 estaduais. Em 1996, além de eleger pela terceira vez consecutiva o prefeito de Porto Alegre, já no primeiro turno, o PT elege 25 prefeitos, 34 vice-prefeitos e 353 vereadores no estado. Com 1.093 .059 votos (18,96\% do total), o PT alcançou o terceiro lugar no Rio Grande do Sul, ficando atrás apenas do PMDB e do PPB, mas superando, pela primeira vez, o PDT.

Não é apenas a evolução histórica do partido que explica a ascensão de Olívio Dutra nas eleições de 1998. O candidato Fernando Henrique Cardoso também foi derrotado no Rio Grande do Sul. Pela terceira vez consecutiva, Luís Inácio Lula da Silva ganhava as eleições para presidente no Estado. Foram $49,05 \%$ dos votos válidos (2.460.551 eleitores) contra $40,60 \%$ para FHC (2.036.805 eleitores).

Há que se analisar ainda as propostas dos dois candidatos. Antônio Britto, em entrevista à revista $P$ ress, ${ }^{23}$ diz que perdeu a reeleição pela reação 74 dos setores latifundiários, de São Borja a Bagé, contra o governo federal e a aliança que fizeram com o PT, onde tiveram de fato uma vitória extraordinária. [...] O fato de que houve no segundo turno todo aquele mal-estar nacional sobre a crise econômica mundial, o Fernando Henrique tomando providências e tal. Tais insatisfações decorrentes do fato de que fizemos um processo de reformas muito forte, e as reformas fazem inimigos $\grave{a}$ vista e aliados a prazo.

Já Olívio Dutra, em entrevista a Isto $\dot{E}_{,}{ }^{24}$ falando de suas propostas e de seu governo, diz:

Não queremos um Estado máximo, burocrático, pesado, custoso, centralizado e autoritário. Nem o Estado minimo, irresponsável socialmente porque ele é minimo para a maioria da população, mas é máximo para os grandes grupos econômicos. Os neoliberais gostam muito de falar nas corporações dos funcionários públicos, mas a GM e a Ford também são corporações.

As duas hipóteses iniciais, complementares, a serem trabalhadas na pesquisa são: a) Antônio Britto perdeu as eleições, mesmo com todo o apoio já referido e um cenário a seu favor, porque a sua candidatura esteve, desde o início, vinculada à reeleição de Fernando Henrique Cardoso, com programas 
e propostas semelhantes para o Estado e para o país, rejeitadas duplamente aqui no Estado; b) Olivio Dutra venceu as eleições porque o cenário que se desenhou com a sua ida para o segundo turno foi outro. Ele teve o apoio de setores descontentes com a política de FHC (principalmente exportadores e da área agrícola), do funcionalismo público estadual, do PDT (que nacionalmente já fazia parte da chapa de Lula, tendo como vice o pedetista gaúcho Leonel Brizola), e por ser uma alternativa ao atual modelo econômico implantado no país. Além disso, a experiência de Porto Alegre contribuiu, principalmente durante o HPEO, no segundo turno. ${ }^{25}$

Para a verificação destas hipóteses, vai ser analisada a maneira como esta disputa foi retratada e também construída pelos dois principais jornais da imprensa gaúcha, desde o início de 1998 até o resultado final das eleições, em outubro; o apoio ou o repúdio a uma das duas principais candidaturas ao governo pelas empresas de comunicação e o reforço ou construção de um cenário favorável a uma delas, hegemônico ou contra-hegemônico. Vai ser analisado também como isto se deu e se refletiu no fazer jornalístico: nas pesquisas analisadas por eles; nos editoriais que abordaram o período e os problemas do estado e do país nos itens desemprego, agricultura e privatizações, bem como o tratamento dado à política e ao jogo político pelos comentaristas especializados. Além dos dois jornais, analisados diariamente durante dez meses, a construção dos cenários de um e outro candidato vai ser composta também pela análise dos debates entre os candidatos na televisão e pelo HPEO, veiculado gratuitamente para todo o estado.

Uma terceira hipótese é a de que a crise na Rússia, que começou a dar sinais em julho e se agravou em agosto (o terror de agosto, como foi chamado por Zero Hora), com queda nas bolsas em todo o mundo, recessão e instabilidade financeira, contribuiu para a reeleição de Fernando Henrique Cardoso (o homem do real, que trouxe a estabilidade e que sabia conduzir o Brasil em situações de crise), mas acabou atrapalhando e desfavorecendo Antônio Britto, já que setores importantes da economia gaúcha perderam com a crise e com as medidas tomadas pelo governo federal para evitar a fuga de capitais do país.

Para o pensador italiano Antonio Gramsci, não existe projeto hegemônico que não tenha como referência as posições dos grupos na estrutura econômica. Mas um determinado grupo social, mesmo detendo o poder da máquina estatal, e sendo o grupo fundamental na atividade econômica, pode fracassar no seu projeto politico e cultural, deixando de ser dirigente. Surge, então, uma crise orgânica entre governantes e governados. O conteúdo desta crise, segundo Gramsci, é a crise de hegemonia da classe dirigente, que ocorre ou porque a classe dirigente faliu em determinado grande empreendimento político pelo qual pediu ou impós pela força o consentimento das grandes massas (como a guerra), ou porque amplas 
massas (especialmente de camponeses e pequenos burgueses intelectuais) passaram de repente da passividade política a certa atividade e apresentaram reivindicações que, no seu complexo desorganizado, constituem uma revolução. Fala-se de "crise de autoridade", mas, na realidade, o que se verifica é a crise da hegemonia, ou crise do Estado no seu conjunto. ${ }^{26}$

\section{Os candidatos}

Antônio Britto nasceu em Santana do Livramento em 1952, filho de pai jornalista e mãe dona-de-casa. Aos dez anos, com a morte do pai, a familia se mudou para Porto Alegre. Trabalhou como jornalista, mesmo não tendo terminado o curso, no Grupo Sinos, na Rádio Guaiba, na RBS TV. Depois, mudou-se para Brasilia, trabalhando como editor político e repórter da TV Globo. É na Capital Federal que ficou conhecido nacionalmente, como portavoz de Tancredo Neves, quando, em cadeia nacional, revelou ao Brasil a morte do futuro presidente da República, já filiado ao PMDB. Foi deputado federal. Em 1988, disputou a prefeitura de Porto Alegre contra Olívio Dutra, do PT. Fez 72.072 votos contra 247.506 de Olívio. Depois, foi ministro da Previdência e Assistência Social, junto com o futuro presidente Fernando Henrique Cardoso, no governo de Itamar Franco (vice de Fernando Collor de Mello, que sofreu impeachment). Chegou a ser cotado para disputar a eleição para presidente da República pelo PMDB em 1994, mas foi barrado por Orestes Quércia e acabou disputando as eleições para o governo do Rio Grande do Sul. Venceu, no segundo turno, por 2.679.701 contra 2.453.174 para Olivio Dutra. Em 1998, disputou a reeleição para ọ governo do Estado, mas perdeu no segundo turno para o mesmo adversário de 1994 e 1988, Olívio Dutra.

Olívio Dutra nasceu num rancho de chão batido em uma fazenda do município de Bossoroca, região das Missões, em 10 de junho de 1941. Segundo ele, conheci a pobreza ao abrir os olhos pela primeira vez. Filho de Amélia e Cassiano, de família humilde, teve que trabalhar desde cedo. Primeiro no Banco do Estado do Rio Grande do Sul (Banrisul) de São Luiz Gonzaga e depois na capital gaúcha. Em 1975, foi eleito presidente do Sindicato dos Bancários. Foi um dos fundadores do PT em 1979. Exerceu o cargo de presidente do Partido no Estado até 1986. É formado em Letras, pela Universidade Federal do Rio Grande do Sul. Em 1982, foi o primeiro candidato a governador pelo PT, no Estado, ficando em quarto lugar. Em 1986, foi eleito deputado federal constituinte mais votado do partido e considerado Constitutinte Nota 10 pelo relatório de avaliação do Departamento Intersindical de Assessoria Parlamentar (DIAP). Dois anos mais tarde, tornouse prefeito de Porto Alegre. Em 1994, perdeu as eleições no segundo turno para Antộnio Britto, voltando a exercer o cargo de presidente do PT gaúcho 
em 1995. Em 1996, aposentou-se como bancário e, em 1998, foi eleito governador do Estado em segundo turno.

\section{Os Partidos}

\section{O PMDB de Antônio Britto}

O Partido do Movimento Democrático Brasileiro surgiu em 30/01/1980, a partir do antigo MDB. O Movimento Democrático Brasileiro foi fundado em 1965, por imposição do bipartidarismo legal imposto pela ditadura militar, instaurada em 1964 (o outro partido era a Arena). O MDB foi um pólo aglutinador das oposições e durante 15 anos não teve dificuldade em manter sob o mesmo teto liberais e organizações de esquerda clandestinas. Mas, com a reabertura democrática, a migração de setores da esquerda para o PT e o PDT, e a adesão dos ex-arenistas ao PMDB, começou a se manifestar uma crise de identidade.

A morte do presidente eleito Tancredo Neves, ${ }^{27} \mathrm{em} 21 / 04 / 1985$, acelerou o processo. O comando do país passou para José Sarney (vice na chapa de Tancredo), ex-PDS, ex-Arena. Sua base de sustentação, a Aliança Democrática, reunia desde o PFL até os partidos comunistas. Em 1986, embalado pelo Plano (econômico) Cruzado, chegou ao auge do poder, elegendo 22 governadores. A única exceção foi o governo de Sergipe. Após o fracasso do Plano, e com a volta da inflação, o PMDB expõe suas divisões. O maior racha aconteceu em 1988, devido às polêmicas durante a Constituinte, com a decisão do PMDB em favor de cinco anos de mandato para Sarney e à opção quanto ao sistema de governo. Fernando Henrique Cardoso e Mário Covas, descontentes, porque defendiam o parlamentarismo e quatro anos para Sarney, saem do partido e formam o PSDB ${ }^{28} \mathrm{Com}$ a saida dos tucanos, Orestes Quércia emerge como líder apoiado pelo MR-8, grupo originário da guerrilha. Ulysses Guimarães ainda era a única unanimidade. ${ }^{29} \mathrm{Com}$ a sua morte, em 1992, num acidente de helicóptero, sepultaram-se as esperanças de unificar o partido. Em 1998, mesmo dividido, o PMDB ainda era um partido importante, com 6 milhões de filiados. Comandava os executivos de 8 Estados, tinha 21 senadores, 86 deputados federais e 1.298 prefeitos.

Entre os princípios básicos do novo Programa do PMDB, aprovado em Convenção Nacional, em 1994, e ratificado para publicação e registro, em $1996,{ }^{30}$ o partido pretende continuar sendo a expressão politica da maioria da população brasileira, oprimida e explorada por um regime econômico voltado para a satisfação de uma pequena minoria. E mais adiante: $O P M D B$ considera que o trabalho é o fundamento da riqueza coletiva e que seus interesses se sobrepõem aos do capital. O emprego e o salário são critérios de decisão em relação aos investimentos públicos. ${ }^{31}$ Para o partido, o novo nome da esperança é desenvolvimento. Desenvolvimento quer dizer criação 
de empregos, desenvolvimento quer dizer salários dignos, desenvolvimento quer dizer multiplicação de empresas pela livre iniciativa. E para que isto aconteça, entre as lições que a história deixou, está a de que

a avalanche neoliberal pretende destruir o Estado brasileiro em nome do ajuste interno e de um hipotético ingresso na modernidade. $O P M D B$ não pretende, em absoluto, manter $o$ Estado tal e qual ele se encontra, servindo aos interesses de uma minoria, marcado pela ineficiência das ações governamentais, pela irracionalidade administrativa. Mas também não concorda com a sua destruição. Reformar o Estado e a esfera pública é hoje um imperativo. [...] O que se busca é o Estado legitimo e necessário, desprivatizado e não corporativista.

\section{O PT de Olívio Dutra}

A idéia de criação de um Partido dos Trabalhadores surgiu em 24/01/ 1979, durante o IX Congresso de Trabalhadores Metalúrgicos, Mecânicos e de Material Elétrico do Estado de São Paulo. Lideranças e ativistas dos movimentos sociais e sindicais aprovaram a proposta feita pelos metalúrgicos de Santo André de se unificarem na construção de um novo partido. No dia 01/05/1979, é lançada a Carta de Princípios do PT: O Partido dos Trabalhadores entende que a emancipação dos trabalhadores é obra dos próprios trabalhadores, que sabem que a democracia é participação organizada e consciente e que, como classe explorada, jamais deverá esperar da atuação das elites privilegiadas a solução dos seus problemas. ${ }^{32}$

No mesmo ano, é lançado o Movimento Pró-PT e eleita a Comissão Nacional Provisória, com 17 representantes. Em ato realizado no auditório do Colégio Sion, em São Paulo, o Manifesto do PT é aprovado por 1200 pessoas e assim surge o Partido dos Trabalhadores, em 10/02/1980 ${ }^{33}$ Entre os diversos setores presentes na sua fundação, professores universitários, representantes de igrejas e dos mais variados movimentos populares e associativos, intelectuais e a nova vanguarda sindical.

A trajetória é lenta e gradual. Em 1982, o PT participa pela primeira vez, com candidaturas próprias, de eleições para todos os niveis. O PT obteve 1,46 milhão de votos $(3,1 \%)$ e conquistou as primeiras prefeituras, em Diadema/ $\mathrm{SP}$ e Santa Quitéria/MA. Elegeu 8 deputados federais e 13 estaduais. Nas eleições de 1985, conquista a prefeitura de Fortaleza e, em 1986, elege 39 parlamentares às Assembléias Estaduais e uma bancada de 16 deputados à Assembléia Nacional Constituinte. No final da chamada Nova República, em 1988, o Partido obtém um crescimento espetacular, conquistando 33 prefeituras, entre as quais, as de três importantes cidades - São Paulo, Porto Alegre e Vitória - e cerca de mil vereadores em todo o país. Em 1989, Luís Inácio Lula da Silva disputa a presidência da República e perde, no segundo 
turno, para Fernando Collor de Mello. Em 1990, o PT elege seu primeiro senador, Eduardo Suplicy, além de 35 deputados federais e 81 estaduais. Em 1992, o PT elege 54 prefeitos e mais de mil vereadores, mas é derrotado em São Paulo e em outros importantes municípios que governava. Dois anos depois, Lula perde a eleição presidencial para Fernando Henrique Cardoso, eleito no primeiro turno, mas elege 49 deputados federais, 89 estaduais, 4 senadores e os dois primeiros governadores, do Distrito Federal e do Espírito Santo. Nas eleições municipais de 1996, o PT duplica o número de administrações, elegendo 115 prefeituras, inclusive a de Porto Alegre, pela terceira vez consecutiva. Somada a votação das 47 maiores cidades, o Partido aparece em primeiro lugar, com 4,8 milhões de votos e surge como segundo partido mais votado nas capitais. Mas sofre derrotas importantes em cidades onde já governava, como Diadema (três gestões consecutivas), Santos (duas gestões), Belo Horizonte, Goiânia e Londrina. Em 1998, Lula perde novamente para FHC, que é reeleito, mas ganha em diversos estados, como Acre, Mato Grosso do Sul e Rio Grande do Sul, além de 7 senadores, 60 deputados federais e 90 estaduais.

De acordo com o Manifesto de Fundação do Partido, o PT nasce da vontade de independência politica dos trabalhadores, já cansados de servir de massa de manobra para os politicos e os partidos comprometidos com a manutenção da atual ordem econômica, social e politica. [...] O PT pretende ser uma real expressão politica de todos os explorados pelo sistema capitalista. ${ }^{34}$

Para mudar esta realidade, o PT defende o socialismo democrático, que deverá não só conservar as liberdades democráticas, duramente conquistadas na sociedade capitalista, mas ampliá-las. A construção desta alternativa democrática e popular se expressa hoje através de uma "Plataforma em Defesa do Brasil", que tem, entre seus itens, a denúncia do acordo com o Fundo Monetário Internacional (FMI); renegociação da divida externa; suspensão imediata de todas as privatizações; fortalecimento dos bancos públicos com direcionamento do crédito para apoio às micro, pequenas e médias empresas; reforma agrária imediata e massiva, acompanhada de politica agrícola que estimule pequenas e médias propriedades e a agricultura familiar; fomento à economia solidária e politica nacional de emprego com redução da jornada de trabalho e fomento aos programas de qualificação profissional..$^{35}$

\section{Conclusões preliminares}

A história do Rio Grande do Sul é marcada desde o seu início por disputas entre dois partidos, dois candidatos, duas propostas, sempre polarizadas. É uma vocação histórica do sistema partidário gaúcho para o bipartidarismo. Para Luiz Pilla Vares, a paixão do gaúcho pela politica está inscrita nas suas origens. O destino do gaúcho é a política, é um predestinado à política. 
Nasceu como tal. Sua história é uma história de guerras, revoluções, idéias. [...] Se existe lugar onde a politica penetrou profundamente na alma popular, este é o Rio Grande do Sul. Política se discutia nas ruelas da velha Rio Pardo, nos bairros operários, na hora do amargo chimarrão, nos galpões das estâncias. Os peões tomavam partido e se criavam ouvindo histórias de revoluções. ${ }^{36}$

Esta é uma situação que se perpetua na história politica gaúcha. Em 1998, o estado se dividiu durante as eleições, e o resultado nas urnas refletiu esta polarização. Os meios de comunicação tiveram um papel importante, reforçando ou desqualificando candidatos e programas, consolidando ou questionando a hegemonia de um grupo no poder.

O jornal Zero Hora, que tem uma circulação diária de 154.331 exemplares, segundo o Instituto Verificador de Circulação, e dominical de 235.214, trabalhou orquestradamente na construção de um cenário favorável a Antônio Britto no primeiro semestre de 1998 . Ou seja, as notícias, geralmente favoráveis ao governo, eram destaque na capa do jornal, abordadas nas páginas de política ou de economia, comentadas pelo editor político e se emitia ainda opinião através dos editoriais. As pesquisas também indicavam favoritismo e a vitória de Britto no primeiro turno. $O$ apoio do governo federal era destacado, aplaudido e valorizado. O horário eleitoral também favoreceu Antônio Britto, por ter o maior tempo e o apoio de 11 partidos. Mesmo assim, com todo este cenário a seu favor, teve que disputar um segundo turno para o qual não 80 estava preparado e que o levou a perder a eleição. A unificação dos projetos derrotou duplamente Antônio Britto e Fernando Henrique Cardoso no Estado, mas Fernando Henrique compensou a derrota no Rio Grande do Sul com a vitória em outros Estados brasileiros e conquistou a Presidência da República já no primeiro turno da eleição. Com Antônio Britto, a história foi diferente.

Já o jornal Correio do Povo, que tem uma circulação diária de 180.266 exemplares e dominical de 180.861 exemplares, segundo o mesmo Instituto, também trabalhou orquestradamente. Mas contra o governo FHC, na capa, nas notícias, nos editoriais e nos comentários políticos feitos pelos articulistas. As pesquisas realizadas tiveram um destaque e um indice diferente das divulgadas pelo jornal Zero Hora. E se não houve um apoio explícito à candidatura Olívio Dutra, também não houve um apoio favorável ao candidato Antônio Britto.

Se a midia teve papel importante e buscou influenciar no resultado da eleição, outros fatores contribuíram para um resultado considerado, por muitos, inesperado. A economia brasileira entrara em crise, em função do mercado internacional, das políticas públicas que não conseguiam fazer diminuir o desemprego, e a exclusão social. O crescimento da economia gaúcha não conseguira passar de $0 \%$, em 1998 . Setores importantes, como o funcionalismo público estadual, pequenos e grandes agricultores, e 
exportadores, estavam descontentes com o governo gaúcho. A sociedade civil se fortalecia e buscava participar e ser ouvida. Todos estes fatores levaram à construção de um contra-cenário, favorável a Olivio Dutra e que, se não teve um porta-voz direto, encontrou o apoio do jornal Correio do Povo e um programa eleitoral muito criativo e dinâmico. Também a estratégia de partir para o ataque e acusar o adversário por não cumprir com a palavra no caso da venda das estatais CEEE (Companhia Estadual de Energia Elétrica) e CRT (Companhia Rio-Grandense de Telecomunicações) mostrou-se muito eficiente. Como diz Przeworski, citando Gramsci, a contagem de votos é a cerimônia final de um longo processo. Esse processo consiste em formar imagens da sociedade, forjar identidades coletivas, mobilizar comprometimentos com visões especificas do futuro. [...] A identidade coletiva, a solidariedade de grupo e o comprometimento politico são continuamente forjados - moldados, destruidos e remodelados - em conseqüencia de conflitos no decorrer dos quais partidos politicos, escolas, sindicatos, igrejas, jornais, exércitos e empresas procuram impor às massas uma determinada visão da sociedade. ${ }^{37}$

E quem ganha com esta disputa, com este embate politico que culmina com as eleições é a democracia. Para Przeworski, a democracia se define como um regime no qual os cargos governamentais são preenchidos em conseqüência de eleições competitivas ${ }^{38} \mathrm{Um}$ regime só é democrático se a oposição estiver autorizada a competir, vencer e tomar posse dos cargos, principalmente o cargo de chefe do executivo e as cadeiras do corpo legislativo. Segundo o autor, as eleições podem ser consideradas democráticas se preencherem três requisitos: incerteza ex ante, ou seja, há uma probabilidade de que ao menos um membro da coalizão situacionista possa perder seu cargo numa rodada eleitoral em particular; irreversibilidade ex post, que é a garantia de que o vencedor das eleições, seja lá quem for, esteja autorizado a tomar posse de seu cargo; e repetibilidade, ou seja, todos os resultados políticos devem ser temporários: os derrotados não perdem o direito de competir no futuro, de negociar novamente, de influenciar a legislação, de pressionar a burocracia ou de recorrer ao judiciário.

Apesar de todos os problemas e desafios apontados no início deste artigo, das críticas e desconfianças dos analistas, as eleições de 1998 para os governos do pais e do estado, preencheram esses três requisitos, o que demonstra que a democracia está se consolidando e fortalecendo no Brasil. 


\section{Bibliografia}

AMARAL, Roberto. É preciso lembrar para jamais esquecer, in Comunicação e Política, vol. V, n. 3, set/dez 1998, ps.14-15.

Caderno de Formação "O PT faz história", Fundação Perseu Abramo, São Paulo. Dezembro de 2001.

Estatuto, Código de Ética, Programa Partidário do PMDB. Diretório Estadual do Rio Grande do Sul. 1996.

GRAMSCI, Antonio. Maquiavel, a politica e o estado moderno. Rio de Janeiro, Civilização Brasileira. 1989.

GRUPPI, Luciano. O conceito de hegemonia em Gramsci. Rio de Janeiro, Graal. 1978.

KUCINSKI, Bernardo. A síndrome da antena parabólica. Ética no jornalismo brasileiro. São Paulo, Fundação Perseu Abramo. 1998.

LIMA, Venício. Mídia, teoria e política. São Paulo, Fundação Perseu Abramo. 2001.

MARQUES, Luiz. Rio Grande do Sul - A vitória da esquerda, Petrópolis, Vozes. 1998.

PILLA VARES, Luiz. "A ideologia gaúcha dos farrapos ao getulismo". In:

Nós, os gaúchos.Porto Alegre, Editora da Universidade/UFRGS. 1995, ps. 139-144.

PORTO, Mauro. As eleições municipais em São Paulo. In: Matos, Heloíza (org). Mídia, eleições e democracia. São Paulo, Página Aberta. 1994, p. 135. PRZEWORSKI, Adam. Capitalismo e social-democracia. São Paulo, Companhia das Letras. 1989.

PRZEWORSKI, Adam; ALVAREZ, Michael; CHEIBUB, José Antônio e LIMONGI, Fernando. O que mantém as democracias? In: Lua Nova, São Paulo, n.40/41, 1998, ps. 113-135.

WOLF, Mauro. Teorias da Comunicação. Lisboa, Presença. 1986.

\section{Notas}

${ }^{1}$ LIMA, Venício. Midia, teoria e politica. São Paulo, Fundação Perseu Abramo. 2001, ps. 175-212.

${ }^{2}$ GRUPPI, Luciano. O conceito de hegemonia em Gramsci. Rio de Janeiro, Graal. 1978, p. 3 .

${ }^{3}$ GRUPPI, Luciano. Op. Cit., p. 59.

${ }^{4}$ PORTO, Mauro. "As eleições Municipais em São Paulo". In: Matos, Heloiza (org). Mídia, eleições e democracia. São Paulo, Página Aberta. 1994, p. 135. ${ }^{5}$ LIMA, Venício. Op. Cit., ps. 180-181.

${ }^{6} \mathrm{KUCINSKI}, \mathrm{Bernardo}$. A sindrome da antena parabólica. Ética no jornalismo brasileiro. São Paulo, Fundação Perseu Abramo. 1998, p. 23.

${ }^{7}$ WOLF, Mauro. Teorias da Comunicação. Lisboa, Presença. 1986, p. 130. 
${ }^{8}$ Dados do Tribunal Superior Eleitoral (TSE) consultados no site www.tse.gov.br. As informações também estão disponíveis em Zero Hora, $31 / 07 / 98$, p. 6. A partir de agora, todos os dados utilizados neste trabalho sobre as eleições são deste site.

${ }^{9}$ A escolha de Amapá e Roraima ocorreu por serem os dois estados mais isolados e com menor infra-estrutura do pais. Alagoas e Rio de Janeiro foram escolhidos pelo TSE por seu histórico de eleições fraudulentas. E o Distrito Federal foi escolhido por ser formado por apenas uma grande cidade, Brasília. 10 AMARAL, Roberto. É preciso lembrar para jamais esquecer, in Comunicação \& Política, vol. V, n. 3, set/dez 1998, ps. 14-15.

"Declaração do Conselho Permanente da CNBB diante das eleições de 1998, in Comunicado Mensal n. 523, Ano 47, julho/agosto de 1998, p. $1369-$ 1371.

${ }^{12} \mathrm{O}$ horário eleitoral é obrigatório, mas não é gratuito, já que as empresas de comunicação recebem isenção no imposto de renda para sua veiculação $\mathrm{e}$ $100 \%$ do preço de tabela.

13 "Coligação Rio Grande Vencedor", formada pelo PMDB, PPB, PSDB, PTB, PFL, PL, PSD, PSL, PSC, PRP e PT do B.

14 "Coligação Frente Popular", formada pelo PT, PSB, PCB e PC do B.

${ }^{15}$ Carta Capital, n. 74, 27/05/98. Consulta realizada pela internet, no endereço www.cartacapital.com.br.

${ }^{16}$ Correio do Povo, 27/02/98, p. 4.

${ }^{17}$ O pedido foi feito no dia 25 de junho e aprovado em 7 de julho pela Assembléia Legislativa.

${ }^{18}$ Zero Hora, 20/07/98, p. 6. O Estado é estratégico para a reeleição de Fernando Henrique no primeiro turno. O presidente perdeu no Estado, em 1989 e 1994, para Lula, e pesquisa realizada pelo Datafolha, entre 12 e 14/08/98, com 10.289 eleitores, revela que o Rio Grande do Sul tem a pior avaliação do governo FHC do pais: 5,3, contra a nota média de 6 .

${ }^{19}$ Se compararmos também a nível nacional, FHC e a "Coligação União, Trabalho e Progresso" (PSDB, PFL, PPB, PTB, PSD e PSL), tinha 23 minutos e 41 segundos do horário eleitoral gratuito, contra 10 minutos de Luís Inácio Lula da Silva, da "Coligação União do Povo, Muda Brasil" (PT, PDT, PC do B, PSB, PCB e PCO).

${ }^{20}$ Britto recebeu $52,21 \%$ dos votos válidos, o que corresponde a 2.679 .701 eleitores, contra $47,79 \%$ de Olívio, num total de 2.453 .174 votos válidos.

${ }^{21}$ A Frente Popular surgiu em 1988, com a disputa de Olívio Dutra para a Prefeitura de Porto Alegre, contra Antônio Britto. A coligação foi formada pelo PT, PSDB (que só participou naquele ano da Frente) e PCB.

${ }^{22}$ Em 1982, elegeu o primeiro e único vereador nos três Estados do Sul: Antônio Hohlfeldt, hoje vereador pelo PSDB em Porto Alegre.

${ }^{23}$ Press, Ano II, n. 15, 2002, p. 15. 
${ }^{24}$ Isto $E$, n. 1518 , de $04 / 11 / 98$. A consulta foi realizada através do site www.istoe.com.br.

${ }^{25}$ Luiz Marques afirma que qualquer explicação para o sucesso' da candidatura da Frente Popular no pleito para o governo (do estado em 98) deve necessariamente passar pelo OP (orçamento participativo). Todavia, o OP não será objeto de análise neste estudo. In: MARQUES, Luiz. Rio Grande do Sul - A vitória da esquerda, Petrópolis, Vozes. 1998, p. 43. ${ }^{26}$ GRAMSCI, Antonio. Maquiavel, a politica e o estado moderno. Rio de Janeiro, Civilização Brasileira. 1989, p. 55.

${ }^{27}$ Tancredo Neves venceu a disputa para presidência da República contra Paulo Maluf(PDS), no Colégio Eleitoral.

${ }^{28}$ Partido da Social Democracia Brasileira, fundado em 25/06/1988. No novo partido, encontram-se outros dissidentes, como José Serra e Franco Montoro. ${ }^{29}$ Como candidato, ele fracassa. Nas eleições para a Presidência da República, em 1989, chega em sétimo lugar. Quem ganha a eleição é Fernando Collor de Mello.

${ }^{30}$ Estatuto, Código de Ética, Programa Partidário do PMDB. Diretório Estadual do Rio Grande do Sul. 1996. Item Programa, ps. 43-68.

${ }^{31}$ No item do programa que fala sobre uma nova política de renda, o PMDB defende a melhoria salarial, relações trabalhistas com autonomia sindical, negociações coletivas e direito de greve. $E$ afirma:

o PMDB permanecerá ao lado dos trabalhadores para tornar realidade todas as propostas que impliquem melhoria efetiva do salário real, com aumento do seu poder aquisitivo. Op cit., ps. 58-59.

32 "Carta de Princípios" lançada publicamente no dia 01/05/1979 e publicada no Caderno de Formação "O PT faz história, Fundação Perseu Abramo, São Paulo. Dezembro de 2001, p. 60.

${ }^{33}$ Em agosto de 1981, acontece o Primeiro Encontro Nacional do PT, e em setembro, a Primeira Convenção Nacional referenda o Diretório Nacional, o Manifesto, o Programa e o Estatuto do Partido dos Trabalhadores.

${ }^{34}$ Manifesto aprovado pelo Movimento Pró-PT, em 10/02/1980, e publicado no Diário Oficial da União de 21/10/1980.

${ }^{35}$ A "Plataforma em Defesa do Brasil" faz parte do "Programa da Revolução Democrática", aprovado no II Congresso Nacional do PT, realizado em Belo Horizonte, entre os dias 24 e 28/1 1/1999.

${ }^{36}$ PILLA VARES, Luiz. "A ideologia gaúcha dos farrapos ao getulismo". In: Nós, os gaúchos. Porto Alegre, Editora da Universidade/UFRGS. 1995, ps. 139-144.

${ }^{37}$ PRZEWORSKI, Adam. Capitalismo e social-democracia. São Paulo, Companhia das Letras. 1989, ps. 121-122. 
${ }^{38}$ PRZEWORSKI, Adam; ALVAREZ, Michael; CHEIBUB, José Antônio e LIMONGI, Fernando. O que mantém as democracias? In: Lua Nova, São Paulo, n.40/41, 1998, ps. 113-135. 


\section{Palavras-chave}

1. Comunicação

2. Política

3. Eleições

4. Hegemonia

5. Cenário de Representação Política (CR-P) 